\title{
Los barbones 0 bethlemitas, la Orden Hospitalaria Americana rescatada del olvido por las Iradiciones de Palma
}

\author{
Juan Carlos Adriazola Silva \\ Universidad Nacional de Piura \\ adriazola46@yahoo.es
}

\section{Resumen}

En la memoria colectiva de los peruanos del presente, el nombre de la Orden Hospitalaria de los Betlemitas está prácticamente olvidado. Sin embargo, al leer las Tradiciones peruanas de Ricardo Palma, el nombre de aquella institución religiosa que permaneció en el Perú por casi trecientos años vuelve a resurgir con nuevos bríos para abrirnos el panorama de una época interesante de la historia de la medicina y de la salud de nuestros antepasados. Junto con esta visión histórica, viene también la parte literaria, que nace de la pluma ingeniosa de Palma, al contarnos acerca de personajes, costumbres y hechos que ya no existen en la Lima actual. Por otra parte, este trabajo intenta explicar muchos de los aspectos que se necesitan conocer para entender mejor la tradición: "Los Barbones", y con ello revalorar el papel de historiador acucioso y de literato ingenioso que fue el padre de las Tradiciones peruanas.

Palabras clave: Tradición, hospitales virreinales, betlemitas, Orden betlemita, medicina en siglo XVII en Lima.

\section{Abstract}

In the collective memory of the Peruvians of the present, the name of the Hospital Order of the Betlemites is practically forgotten. However, when reading the Peruvian Traditions of Ricardo Palma, the name of that religious institution that remained in Peru for almost three hundred years, resurfaces with new vigor to open the panorama of an interesting time in the history of medicine and the health of our ancestors. Along with this historical vision, comes also the literary part, which is born from the ingenious pen of Palma, when telling us about characters, customs and facts of a Lima that no longer exists. This communication will try to explain many of the aspects that need to be known in order to better understand the 
tradition: "The Barbones", and with this, to revalue the role of a diligent historian and an ingenious writer who was the father of the Peruvian Traditions.

Keywords: Tradition, viceregal hospitals, Betlemites, Betlemite Order, medicine in Lima in the 17th century.

Juan Carlos Adriazola Silva, Doctor en Educación por la Universidad Nacional de Piura. Magíster en Investigación y Docencia por la Universidad Nacional Pedro Ruiz Gallo de Lambayeque. Periodista por la Universidad de Piura. Diplomado en Relaciones Internacionales por la Academia Diplomática del Perú. Miembro del Instituto de Estudios Histórico Marítimos del Perú, Centro de Estudios Histórico Militares e Instituto Libertador Ramón Castilla, entre otros. 


\section{¿Cómo se inició el interés por el tema?}

En una amena tertulia que se realizó los primeros días de agosto de 2002, en la Casa Museo Gran Almirante Grau de Piura, gracias al anfitrionaje y cordial amistad de quien era a la sazón su directora, doña Isabel Ramos Seminario, comentábamos los contertulios allí reunidos un acontecimiento sucedido pocos días antes, más exactamente el 30 de julio, en la capital de Guatemala, cuando el papa Juan Pablo II, en multitudinaria ceremonia durante su tercer viaje a ese país, elevó a los altares, luego de un proceso de canonización de 304 años, al hermano Pedro de San José Betancourt, dicho sea de paso el primer santo católico de Centroamérica.

En esa tertulia, dos asuntos llamaron mi atención: primero, lo dilatado del tiempo que me pareció su proceso canónico y segundo, que salió a la luz algo que personalmente no conocía entonces, y era la relación que unía a dicho santo con el Perú y muy particularmente con mi tierra natal San Miguel de Piura. Y es que en la historia hospitalaria de nuestro país y en el de la ciudad norteña los frailes de la Orden Hospitalaria de Nuestra Señora de Bethlem ${ }^{1}$ tuvieron presencia significativa por varios siglos, haciéndose cargo de hospitales de incurables y casas de convalecencia desde su llegada a nuestra patria en la segunda mitad del siglo XVII.

Isabel Ramos al ver mi gran interés por los temas señalados, me sugirió que leyera la tradición "Los Barbones" de Ricardo Palma, pues seguro que en ese relato encontraría algunos

l Esta palabra deriva de Bethlehem o Bethlen, en español Belén, pueblo de la antigua Palestina donde nació Jesucristo. De dicha denominación surgen varios nombres y adjetivos de pertenencia o gentilicios. Según la documentación de archivo consultada se encontró: bethlehemitas, bethlemitas, betlehemitas, betlemitas, belethmita, beletmitas, belemitas o beletmos, válidas en todos los casos. 
datos básicos que satisfacerían mi curiosidad. Debo confesar que en ese tiempo aún no estaba muy familiarizado con la obra palmista, como lo estoy ahora, de tal modo que aquella sugerencia abrió para mí las puertas de un mundo apasionante, pero lleno de muchas interrogantes. Desde entonces hasta la actualidad el tema de los betlemitas guarda para mí un especial interés, el cual me ha llevado en los últimos años a investigarlo en archivos civiles tan importantes como el Regional de Piura, el de La Libertad, el Archivo General de la Nación, así como en archivos eclesiásticos como el del Arzobispado Metropolitano de Piura, el de Trujillo y el de Lima, además de otros repositorios que guardan valiosísima información en la capital de Guatemala y en el Archivo Secreto Vaticano. Tengo la esperanza que lo reunido hasta ahora algún día se publique en forma de libro.

\section{Las órdenes religiosas en las Tradiciones}

Para quienes han tenido la oportunidad de leer las Tradiciones peruanas y analizar sus diversos contenidos, no es raro que hayan encontrado innumerables menciones a las principales órdenes religiosas que llegaron desde la época de los conquistadores hasta las que arribaron en la última etapa del virreinato. Así, de la primera hora son los dominicos, los mercedarios y los franciscanos (Fernández, 2000: 82-88); más tarde llegarán los jesuitas y los agustinos (Ibíd.: 110-126); ulteriormente, los de la Congregación del Oratorio de San Felipe Neri; los de la Orden de los Clérigos Regulares Ministros de los Enfermos o Padres de la Buena Muerte, llamados camilos por su fundador San Camilo de Lelis; y los de la Orden de San Benito, etc.; cada uno de ellos con un carisma y espiritualidad particular. A varias de esas órdenes, Palma tratará en términos jocosos, pintorescos y hasta irreverentes, pero en otros casos, como el de los jesuitas, el tradicionista destilara "lava y tinta", como 
bien ha explicado Miguel Ángel Rodríguez Rea (2007: 233246). Pero serán dos las órdenes religiosas hospitalarias de mayor mención en el corpus palmino: la Orden hospitalaria de San Juan de Dios (los juandedianos), nacida en Granada, como parte de la Corona de Castilla; y la Orden Hospitalaria de Nuestra Señora de Bethlem (los betlemitas), originaria de la antigua Guatemala, en el Virreinato de Nueva España. Al referirse a dichas órdenes hospitalarias, Palma tendrá palabras de elogio y respeto por la labor humanitaria que desempeñaron siempre con su prójimo.

\section{Pedro Betancourt, el fundador}

El fundador de la Orden betlemítica fue el hermano Pedro de San José Betancourt. Este santo varón nació en la villa de Vilaflor de Chasna, isla de Tenerife, una de las siete que conforman las llamadas Islas Canarias, a principios del año 1626 (no hay fecha exacta del día de su nacimiento). Tuvo por nombre único el de Pedro, que su padre Amador González y su madre Ana García le pusieron en homenaje a San Pedro Apóstol, patrón de la parroquia de su pueblo natal. El paisaje que rodea a Pedro desde su infancia está marcado por dos elementos geográficos importantes: la presencia del volcán Teide y el eterno azul marino del océano Atlántico. En este entorno de singular belleza, solaz y tranquilidad, Pedro Betancourt encontró las bases de la santidad que luego florecería admirablemente en la América hispana.

El 18 de septiembre de 1649, Pedro, con 23 años de edad, emprendió viaje hacia "tierra de Indias" con la ilusión de convertirse en sacerdote y misionero. Él se embarcó en el puerto de Santa Cruz de Tenerife sin despedirse de sus padres y hermanos, pues sabía que su partida les afligiría. Fue así como dejó su tierra natal para nunca más regresar a ella. 
Betancourt arribó a La Habana, Cuba, el 4 de septiembre de 1649, donde aprendió el oficio de tejedor, mientras aguardaba la oportunidad de encontrar un barco que lo llevara a las costas de Honduras, como en efecto así fue.

Desde el puerto hondureño de Trujillo el joven Pedro viaja a pie hacia la ciudad de Santiago de los Caballeros, antigua capital del Reino de Guatemala, a donde llega el 18 de febrero de 1651. Como consecuencia de la fatiga y la mala alimentación, el joven Pedro enfermó gravemente y fue internado en el Hospital Real de dicha ciudad.

Salvada su vida, debió convalecer en un clima adverso y sin recursos económicos. La penosa experiencia vivida le lleva a meditar profundamente sobre el dolor que atraviesan los enfermos pobres y solitarios. Ésta es la semilla de los futuros hospitales de convalecientes que con el tiempo fundara él y los de su Orden.

Tras sanar completamente continúa con su proyecto inicial de hacerse sacerdote. Ingresa al Colegio de Teología de San Lucas que dirigen los padres de la Compañía de Jesús. Aunque sabía leer, tenía carencias intelectuales que lo limitaban, y decide por ello no continuar con los hijos de San Ignacio de Loyola. Con la ayuda de su director espiritual, el padre Manuel Lobo, S.J., llega a la conclusión que su vocación debe encaminarla en otra comunidad religiosa.

Por este motivo, el 10 de enero de 1655 pide su admisión en la Tercera Orden Franciscana, conocida también como los "terciarios", es decir, los seglares que deseaban vivir el espíritu de San Francisco de Asís, pero sin ser religiosos formalmente. El joven Pedro, agregará desde entonces a su nombre de pila el de San José, por la gran devoción que sentía por el casto varón padre de Jesucristo. Pedro de San José, al convertirse en 
terciario franciscano, se entrega por completo a una vida de intensa oración y mortificación, y, poco a poco, a través de la piedad y la caridad, crece su acendrado amor al prójimo.

Tiempo después, el hermano Pedro, al ver la promesa e ignorancia de los niños indígenas, negros y mulatos de su ciudad, siente la necesidad de ayudarles de una forma más efectiva. Por ello, crea una escuelita de primeras letras, donde, además, se preocupa por enseñarles los rudimentos de la "Doctrina Cristiana". Con los años, la escuelita se amplía a oratorio, convento e iglesia; luego, vendrá la fundación del primer hospital de convalecientes que pondrá bajo la advocación de Nuestra Señora de Belén. Su deseo era incorporar a más hermanos de la Tercera Orden en estas tareas sociales, pero esto generó un conflicto con los superiores franciscanos, pues aquel proceder no se acomodaba al quehacer propio y al carisma de la Orden seráfica. Con todo, no se desanimó en su propósito y siguió en la brega.

\section{La creación de la Orden betlemítica}

El hermano Pedro, sin buscarlo, fue configurando con su labor apostólica una nueva orden hospitalaria, ya denominada entonces Comunidad de Bethlem pues se inspiró en el ministerio del nacimiento de Cristo para establecer las bases de su comunidad, carisma y espiritualidad, con la que la Iglesia se vería enriquecida con el paso del tiempo. El mismo Pedro de San José Betancourt redactó un reglamento con el régimen de vida propio, con los distintos actos que deben cumplir los hermanos en la vida conventual y en el trabajo del hospital. El hermano Pedro murió santamente el 25 de abril de 1667, cuando las constituciones de las órdenes aún estaban en borradores. Por deseo expreso del mismo Pedro de San José Betancourt, fue elegido fray Rodrigo de la Cruz como Hermano Mayor o General de la nueva familia religiosa. 
Fray Rodrigo (conocido en el mundo como Rodrigo Arias de Maldonado y Góngora) había nacido en Marbella, Málaga. Era de una ilustre familia entroncada con algunas casas nobles de la península, entre ellas la de Alba y la de Benavente. Fue gobernador de Costa Rica con solo veintidós años. Conquistó para la corona española la región de Talamanca (erróneamente se le ha mencionado en la tradición de Palma como Talamantes, que está en la región española de Zaragoza). Pero cuando sintió el llamado de Dios, luego de una agitada vida amorosa, renunció al marquesado de Talamanca, a la cuantiosa renta que este título llevaba anexa, y a los altos privilegios y cargos que el monarca le habría concedido por sus servicios, consagrando de lleno su existencia al bien de los pobres enfermos. Es gracias a la tesonera labor de fray Rodrigo de la Cruz que el Instituto betlemítico salió adelante, y fue él quien lo introdujo en los diversos países de la América española, durante los cincuenta años que ostentó el generalato de la Orden.

$\mathrm{Al}$ extenderse en todo el continente americano, los betlemitas dividieron su prefectura general en dos provincias: la Provincia de Nueva España (que comprendía México, Centroamérica $\mathrm{y}$ el Caribe) con once hospitales, los cuales se gobernaron desde Guatemala; y la Provincia de Nueva Granada y Nueva Castilla con veintidós hospitales, tuvo como sede Lima, capital del Virreinato del Perú. En 1688, el hermano Rodrigo de la Cruz, para dar mayor cobertura a la asistencia social, fundó la comunidad de religiosas betlemitas, con el propósito de destinarlas a la atención exclusiva de mujeres dentro de los hospitales.

La Orden hospitalaria de Belén, creada en 1660 por el hermano Pedro de San José Betancourt, fue reconocida oficialmente por el papa Clemente X, quién expidió una bula fechada el 2 de mayo de 1672, mediante la cual aprobó los Estatutos de la 
Orden, y le dio el nombre inicial de Compañía ${ }^{2}$ Betlemítica (Zelada, 1773: 1-38).

Más tarde, Inocencio XI, por bula del 26 de marzo de 1687 , le otorgó las exenciones y privilegios concedidos a las órdenes regulares y confirmó, a la vez, sus Constituciones, además de ponerla bajo su pontificia protección. (Ibíd.: 68-107). A diferencia de las otras órdenes existentes (monacales o mendicantes), como los benedictinos, los cartujos, los agustinos, mercedarios, franciscanos, etc., los betlemitas no realizaban su profesión religiosa con votos solemnes, sino con votos simples.

Ratificada la Orden por la Sede Apostólica, los betlemitas tuvieron derecho a poseer "Arma Militare", esto es, "escudo de armas", el cual podía ostentar en los frontispicios de sus conventos, escuelas, iglesias y hospitales, y de ello queda muestra visible en diferentes obras arquitectónicas a lo largo y ancho de toda la América hispana; y en el Perú aún quedan ejemplos notables en los antiguos hospitales de las ciudades de Cajamarca (Complejo Belén), Trujillo y Cuzco. El escudo lleva por divisa las palabras: "gloria in excelsis deo et in terra pax hominibus bonae voluntatis. Laudamus te", que significan: "Gloria a Dios en el cielo y paz en la tierra a los hombres de buena voluntad. Te alabamos". Palabras tomadas expresamente del Evangelio de San Lucas (Lc 2, 14).

\section{Los betlemitas: aspecto físico y formación}

Los betlemitas usaron, como otras órdenes religiosas, hábito talar que lo conformaron una túnica y una capa de paño buriel o pardo. Al principio, lucieron una cruz azul en el pecho, ceñidor de correa y sandalias, siéndoles prohibido montar a caballo.

2 No debe extrañar que en diversos documentos antiguos referidos a los betlemitas, a esta Compañía se le llame también Instituto o Religión. 
La cruz azul se cambió pocos años después por una insignia ovalada con la representación del nacimiento del Hijo de Dios (Jesús, en el pesebre, aparecía flanqueado por la Virgen María y por San José). Esta insignia debía ser portada por cada hermano betlemita al lado izquierdo del pecho.

La circunstancia de usar barba larga, siguiendo la tradición implantada por el hermano Pedro, dio pie para que la gente, en diferentes partes de la América central y meridional, los llamase popularmente como barbones o barbudos.

$\mathrm{Al}$ ser la labor hospitalaria el eje central del quehacer betlemítico, de acuerdo a lo estipulado por el papa Inocencio XI mediante bula de 26 de marzo de 1687, los aspirantes a frailes debían entrenarse de forma intensa y adecuada en el complicado oficio y arte de la medicina, así como también debían tratar de penetrar en los más profundos secretos de la anatomía, la botánica y la química. En los años de formación conventual, era menester que los iniciados colaboraran como asistentes de los frailes de mayor edad y experiencia en las tareas de diagnóstico, tratamiento y cura de todas las enfermedades. Esta preparación tenía efectos prácticos, pues era una forma de medir la vocación de los aspirantes a través del dolor de los enfermos. Y, de paso, templaban su carácter y valor ante cualquier situación difícil que se presentara en el hospital. De este modo, estarían siempre listos para superar las sensaciones de repugnancia, asco, miedo o, incluso, temor a la muerte, sensaciones que, para el común de la gente, podrían ser insoportables; pero que para un fraile betlemita eran una forma de santificación y una ofrenda permanente de su trabajo a Dios.

En los conventos y hospitales betlemíticos existían boticas bien implementadas y verdaderos laboratorios de alquimia, en donde se preparaban y estudiaban una serie de compuestos: jarabes, ungüentos, pócimas, etc., que se recetaban como 
medicina a los pacientes. Es interesante señalar el amplio y rico conocimiento que los frailes betlemitas tenían de las propiedades curativas de las plantas medicinales que abundaban, tanto en la América meridional como en la septentrional, de allí que la farmacopea haya sido parte de la clave de su éxito desde la segunda mitad del siglo XVII hasta comienzos del siglo XIX.

\section{Los betlemitas en el Virreinato del Perú}

En 1669, a Fray Rodrigo de la Cruz, en calidad de Hermano Mayor de la Orden betlemita y primer sucesor del hermano Pedro de San José Betancourt, le fue enviada una invitación para venir al Virreinato del Perú y fundar un convento y hospital betlemítico en Lima. En efecto, el 5 de junio de 1671, Fray Rodrigo salió de Guatemala, en compañía de los hermanos Fray Andrés de San José, Fray Alfonso de la Encarnación y Fray José de la Concepción Villela. Los viajeros desembarcaron en el puerto de Paita el 15 de octubre de 1671 $\mathrm{y}$, desde allí, como era usual entonces, emprendieron camino a lomo de mula hacia la ciudad de Trujillo y luego a la Ciudad de los Reyes. (García, 1956: 384).

En Lima gobernaba a la sazón don Pedro Fernández de Castro, Conde de Lemos, décimo noveno Virrey del Perú. Efectuada la audiencia de rigor, el propio virrey condujo al Hermano Mayor de los betlemitas y a sus acompañantes hacia el Hospital del Carmen, para que a partir de ese momento se hicieran cargo de dicho establecimiento de salud. El Hospital del Carmen, fundado en 1648, estaba destinado a indios convalecientes. Más tarde, el papa Clemente X será quien apruebe la presencia de los betlemitas en ese nosocomio, mediante bula de 3 de noviembre de 1674. Es importante mencionar, que en el Hospital del Carmen se atendían a los enfermos que no podían 
ser recibidos en los hospitales de Santa Ana y San Andrés, los más antiguos de Lima en la época virreinal.

Con el tiempo, un gran contingente de hermanos betlemitas arribó al Perú, para hacerse cargo, además, del Hospital de Santo Toribio, llamado también Hospital del Refugio, y del Hospital de San Juan de Dios de Bellavista.

Al tomar posesión de su cargo el nuevo virrey, don Baltasar de la Cueva Henríquez, no desamparó durante su gobierno a los hermanos betlemitas sino, por el contrario, continuó protegiéndoles y dándoles la ayuda económica que necesitaban para el sostenimiento de sus casas. Igual ocurrirá en el futuro con los virreyes que sucedan en el gobierno del Virreinato peruano. Fruto de estos patrocinios es la fundación de los hospitales en las ciudades de Chachapoyas, Cajamarca, Piura, Trujillo y Huanta. Luego vendrá la fundación del Hospital de Belén del Cuzco, de Potosí, Huaraz, Quito y Moquegua.

El sostenimiento de los hospitales betlemíticos demandaba considerables sumas de dinero que los betlemitas debían cubrir no sólo con la ayuda de las autoridades virreinales sino, también, con ingresos propios como la venta de los diversos medicamentos que ellos preparaban en sus boticas. Muchos fueron los benefactores de los hospitales betlemíticos a lo largo de su historia. De allí que, en las pesquisas que se hacen en los archivos históricos, se encuentren una serie de documentos que tratan de la obtención de rentas directas o indirectas, tales como las capellanías, los censos enfitéuticos y donaciones caritativas ad perpetuam de particulares.

En los hospitales betlemíticos no sólo se atendía a los enfermos y desvalidos, sino las primeras letras, tal como lo hiciera en un inicio el venerable Pedro de San José Betancourt. De este modo, vino a contribuir esta benemérita Orden a la difusión de 
la enseñanza básica en una época en donde había gran escasez de establecimientos educativos.

\section{Comienzan a soplar nuevos vientos}

Al cruzar el siglo XIX un acontecimiento sin precedentes vendrá a influir en la decadencia de las órdenes hospitalarias en el Perú, entre ellas también la de la religión betlemítica; este será la creación del real Colegio de Medicina y Cirugía de San Fernando, fundado el 13 de agosto de 1808 por disposición del virrey don Fernando de Abascal y Souza, a iniciativa del protomédico Joseph Hipólito Unanue.

Los religiosos betlemitas continuaban teniendo, en cambio, el monopolio de la medicina y guardaban con mucho celo los secretos de la farmacopea. Eso sí, el oficio de la medicina lo ejercían por delegación expresa del Protomedicato de Lima.

\section{Los betlemitas y la Independencia}

Ganado terreno en la mente y en el corazón de buena parte de los peruanos, el deseo de emanciparse del dominio español, solo quedó esperar la llegada del ejército del general don José de San Martín para concretar ese anhelo largamente acariciado. En este contexto, la tarde del 7 de septiembre de 1820, la Expedición Libertadora hizo su ingreso en la bahía de Paracas y, al día siguiente, inició el desembarco de sus tropas en el pueblo de Pisco.

Luego de dos meses de preparativos, el 26 de octubre, la Expedición Libertadora abandonó Pisco rumbo al norte por el mar del Callao y Ancón, alarmando a los realistas y entusiasmando a los patriotas. El 11 de noviembre se produjo un nuevo desembarco de las tropas en la playa de Huacho y 
Végueta, pasando a ocupar el pueblo de Huaura, que fue declarado cuartel general de San Martín. Durante esta campaña, el Libertador tuvo progresos notables en su obra emancipadora gracias al apoyo que se le brindó a lo largo y ancho del país. En el norte del Perú destacan, sobre todo, dos sucesos importantes que coadyuvarán al objetivo último: la Independencia de Guayaquil y la Independencia de Trujillo.

Más tarde, en Lima, jurada la Independencia el 28 de julio de 1821 , así como la sociedad civil debió plegarse a la causa de la Independencia, así también los diversos eclesiásticos y los hermanos de todas las órdenes religiosas debieron hacer también lo mismo, con lo cual los betlemitas no fueron la excepción. Iglesias y conventos contribuyeron desde entonces en el sostenimiento de las últimas campañas libertadoras. No obstante, los fondos públicos seguían siendo escasos.

En general, el proceso de la Independencia fue un período histórico de gran agitación y cambios, ante el cual ninguna institución religiosa o clerical pudo ser indiferente. $\mathrm{Al}$ respecto, Jeffrey Klaiber puntualiza:

Después de la Independencia, la Iglesia Católica en el Perú sufrió un serio trastorno en su estructura y funcionamiento institucional. No obstante, en general, no perdió su "status" privilegiado en la sociedad. Los primeros gobiernos republicanos reclamaron para sí el derecho de patronato nacional sobre la Iglesia y sus dependencias, tal como lo tuvo en el pasado la monarquía española. Esta situación provocó, una crisis en la jerarquía eclesiástica: durante un período entre 15 a 20 años la mayor parte de las diócesis estuvieron vacantes. Al mismo tiempo, los liberales intentaron reformar la vida religiosa cerrando numerosos conventos, confiscando sus propiedades y obligando a muchos religiosos a abandonar su estado para pasar al clero 
secular. (...) En términos generales puede decirse que el ataque liberal fue relativamente suave. Los liberales de esta época eran regalistas doctrinarios, pero no anticlericales ni mucho menos antirreligiosos. Su propósito fue controlar la Iglesia con el fin de ponerla al servicio de la Nueva República (1996: 40-41).

En cuanto a las órdenes hospitalarias, debe precisarse que una de sus instituciones más afectadas fue la llamada del Patronato Nacional que venía a ser, aunque con marcadas diferencias, un modelo tomado del Patronato Regio. Esta afectación, junto con otras de carácter legal, vino a colapsar la labor asistencial y médica de los hospitales que por varios siglos habían sido gobernados por religiosos. Sobre el particular, se lee:

En la Ciudad de los Reyes el impacto de las crisis de los regulares en los hospitales había causado grandes estragos. En los primeros años de instaurada la República, solo funcionaban tres hospitales en Lima, habiendo existido diez en la época virreinal. Las órdenes religiosas hospitalarias habían sufrido una merma considerable como resultado de la Constitución dada por las Cortes de Cádiz de 1812 y otras leyes complementarias [como las que se dieron de 1820]. Al crearse la República con San Martín y, más tarde, con el advenimiento del gobierno de Bolívar, se continuó minando los derechos y privilegios de las órdenes religiosas hospitalarias hasta prácticamente desaparecerlas. Esta suerte corrieron los betlemitas, los religiosos de San Juan de Dios (o “juandedianos") y los camilos (o padres de la buena muerte). En el caso específico de los betlemitas las cifras son bastante elocuentes: en 1826, únicamente permanecían en Lima 15 hermanos legos, en 1833, en todo el país sólo quedaban 8 betlemitas. A finales de 1858, parece que los betlemitas simplemente se extinguieron como orden en el Perú. Similar destino corrieron en otras naciones americanas. (Ibid: 167). 


\section{Surgimiento de la Sociedad de Beneficencia}

Antes de la reforma del clero regular de 1826, el supremo gobierno intentó enfrentar la crisis de asistencia hospitalaria creando la primera Sociedad de Beneficencia Pública en 1825. El concepto de la Beneficencia Pública se inspiraba en las sociedades filantrópicas y humanitarias que surgieron en Europa a finales del siglo XVIII y comienzo del siglo XIX, las cuales respondían al ideal liberal que alentaban la máxima participación de los ciudadanos en los asuntos públicos. La beneficencia de cada ciudad se componía de los caballeros y las damas más distinguidas de la sociedad, cuya misión consistía en velar por la buena marcha de los hospitales, los hospicios o asilos, los cementerios y las "loquerías". Sin embargo, las primeras sociedades de la beneficencia no siempre caminaron bien debido a la falta de buena organización y de fondos. En 1848, el gobierno se vio obligado a reorganizar la beneficencia en toda la República, dándole un nuevo impulso.

Al haberse desarraigado a los betlemitas de los hospitales a su cuidado, la labor hospitalaria quedó en manos de una junta de beneficencia, la cual trató de contratar cuanto antes algunos jóvenes médicos graduados en la Facultad de Medicina de San Fernando, para que atendieran de forma permanente a los enfermos del Hospital del Refugio. Paralelamente, comenzó una labor de ayuda social en beneficio de ancianos, mujeres y niños indigentes.

\section{Las devociones betlemíticas}

Como ha quedado mencionado, los betlemitas eran, por Estatutos y Constitución, fieles devotos de la Sagrada Familia, a través del misterio del nacimiento de Cristo, cuya devoción se esforzaron en propagar en todas sus hospitales y conventos 
diseminados en la América hispana. De este modo, los betlemitas siguieron los pasos de su fundador Pedro de San José Betancourt, quien promovió en las calles de la Antigua Guatemala las famosas posadas de Belén y la Festividad de San José, así como otras prácticas de piedad popular: el vía crucis y el rezo del Santo Rosario, la devoción a las almas del purgatorio, diversas procesiones, etc. Famosas fueron en sus conventos e iglesias las celebraciones de la fiesta del nacimiento del NiñoDios a finales de cada año, en donde exponían grandiosos pesebres de cientos de piezas, que eran la admiración y deleite de grandes y chicos.

No debe olvidarse aquí el filial cariño que los betlemitas guardaron siempre a la Santísima Virgen María. Pues así se los dejó también por escrito, en su testamento, el hermano Pedro de San José, como fiel reflejo de lo que había sido su práctica personal y su celo apostólico.

\section{¿Dónde estaba ubicado en Lima el hospital de los Betlemitas?}

Dos fueron los hospitales que la Orden de los frailes betlemitas tuvieron en el cercado de Lima durante la época virreinal:

\section{El Hospital de Nuestra Señora del Carmen}

El primero de ellos fue el Hospital de Nuestra Señora del Carmen (fundado en 1648 por el presbítero Antonio Dávila y el curaca indio Juan Cordero), más tarde conocido por el nombre de Hospital de Barbones. Según ha estudiado Juan Luis Orrego Penagos, la fundación de este hospital permitió que los indios convalecientes que salían del Hospital de Santa Ana no fuesen por "calles y plazas dándose al desorden, contrayendo nuevos y más peligrosos males por accidentes o reincidiendo 
en la enfermedad. Atendiéndose al año tres mil indios y habiendo años en que no moría ni uno solo". (Orrego, 2017: párrafo 4). Estaba ubicado en la "Calle Barbones" o "Calle de Betlemitas", en el Cuartel III, Barrio $2^{\circ}$ de la Ciudad de los Reyes (actual cuadra 15 del jirón Junín), a muy pocos metros de una de las portadas que daban salida al exterior de la Muralla que resguardaba la capital, llamada "Portada del Cercado" o "Portada de Barbones". (Augustín, 2012: 148-150).

Este primer hospital llegó en sus mejores tiempos a tener hasta 150 camas. Sin embargo, después del terremoto de 1687 quedó seriamente afectado en su estructura, por lo que el Hermano Mayor de la Orden Fray Rodrigo de la Cruz (residente entonces en el Perú) pidió su traslado a un terreno aledaño a extramuros, con el propósito de tener allí amplia huerta que proveyera a los enfermos de legumbres y frutos para el sostenimiento diario. Al lado de este hospital se encontraba el convento grande y la iglesia de los betlemitas, del cual hará referencia don Ricardo Palma en sus Tradiciones peruanas, y en donde en cada Navidad se presentaba un nacimiento mecánico que concitaba el interés de los vecinos de Lima. Este aserto lo confirma don José Gálvez Barrenechea en su obra Calles de Lima y meses del año, publicada en 1943, cuando al referirse a los vecinos más antiguos que transitaron por Barrios Altos, menciona a los frailes betlemitas:

A fines del siglo XVII y comienzos del XVIII (...) y más allá del amurallamiento, un nuevo tipo señorea: el del fraile barbón, alquimista, horticultor y juguetero. En el convento -después en parte huerta de la familia Raygada [por el año 1858] - hubo un lindísimo nacimiento famoso en Lima. (p: 134).

Este segundo edificio hospitalario regentado por los betlemitas, brindó atención médica por cerca de 250 años. Desaparecidos los barbones en la primera mitad del siglo XIX, el vetusto hospital 
pasó a ser administrado por la Beneficencia Pública de Lima, sin embargo ello no sería por mucho tiempo, pues el Supremo Gobierno dio la orden para que dicha edificación sirviera de cuartel militar (Cuartel de Caballería Barbones), que hasta la actualidad existe en el límite de Barrios Altos y el distrito del Agustino; sede, primero, del Regimiento de Caballería Mariscal Domingo Nieto, y luego, del Regimiento Húsares de Junín, que históricamente han sido las escoltas de honor del Presidente de la República.

\section{El Hospital del Refugio}

La tarea hospitalaria que desde un inicio desempeñaron los betlemitas en el Hospital del Carmen fue pronto reconocida por propios y extraños, y ello les valió para que en 1702 (Prince, 1890: 33), el virrey Melchor Antonio de Portocarrero y Laso de la Vega, Conde de la Monclova, les hiciese cargo de otro hospital aparte del que ya venían dirigiendo desde décadas antes. Este hospital no era otro que el fundado por el huanuqueño fray José de Figueroa y el capitán español Domingo Cueto, y que primigeniamente ocupó el local del Colegio de Caciques en el Cuartel III, Barrio $1^{\circ}$ de la ciudad (hoy cuadra 12 del jirón Ancash, Barrios Altos). Este nosocomio estuvo dedicado esencialmente a la atención de incurables e inválidos de sexo masculino. El hospital y su iglesia sufrieron daños de consideración con el terremoto de 1746, pero fueron reconstruidos pronto por los betlemitas. Refiriéndose específicamente a la iglesia de la religión hospitalaria mencionada, Manuel Atanasio Fuentes en su obra Guía Histórico-Descriptiva, Administrativa, Judicial y de Domicilio de Lima, editada en 1860, dice: "La única que se conserva en Lima es la del Refugio, fabricada por los padres betlemitas cuando se hicieron cargo del hospital a que es anexa. Está situada en la calle del mismo nombre”. (p. 39). 
En el año 1804, durante el gobierno del virrey Avilés, se creó el hospicio de incurables de mujeres, contiguo al de hombres, gracias a la donación que hizo la dama limeña Marian de Querejazu y Santiago Concha. En 1862, el hospital de betlemitas fue adjudicado a la Beneficencia Pública de Lima; y en 1869, se encargó su administración a la Congregación de la Hijas de la Caridad de San Vicente de Paul (llegadas al Perú en 1858). Históricamente se le conoce con varios nombres: "Hospicio de Incurables", "Hospital el Refugio", "El Refugio de Incurables", "Hospital Santo Toribio de Incurables" y, finalmente, "Hospital Santo Toribio de Mogrovejo" (1933). Este último nosocomio serviría de base al actual "Hospital del Instituto de Ciencias Neurológicas del Perú".

\section{¿Cómo se creó la tradición de "Los Barbones"?}

El éxito que en 1883 obtuvo la sexta serie de Perú. Tradiciones, llevó a don Ricardo Palma a escribir nuevos relatos y a recolectar algunos de los ya publicados en algunos diarios capitalinos. Este proceso debió llevarle aproximadamente seis años de trabajo. De sus recuerdos personales, pesquisas bibliográficas e investigación de archivo, surgió la nutrida tradición que intituló "Los Barbones", en homenaje a aquellos frailes hospitalarios que por casi dos siglos y medio habían ejercido labor caritativa con los pobres enfermos de la Ciudad de los Reyes.

En primer lugar, es interesante advertir a quién don Ricardo Palma dedicó esta tradición. Según Julio Díaz Falconí (2015: registro $\mathrm{N}^{\circ} 352$, p. 162), la crónica de los hospitalarios betlemitas apareció publicada por primera vez en la revista El Ateneo, órgano institucional de "El Ateneo de Lima", datada en junio de 1887 (Año II, tomo III: pp. 360-369). En esta publicación citada, el nombre del homenajeado es Jorge Muelle. El mismo nombre se puede leer también -de acuerdo a la revisión detallada 
hecha de todo el corpus palmino- en la séptima edición de las Tradiciones, que vio la luz en 1889 bajo el título de Perú. Ropa Vieja; igual ocurre en las reimpresiones de 1896, 1911 y 1924. Sin embargo, en la edición de Tradiciones peruanas de Aguilar de 1957, preparada por Edith Palma, la nieta del tradicionista, se cambió quizá por error el nombre de Jorge Muelle por el de Juan Muelle. Todo hace pensar que el homenajeado original de la tradición "Los Barbones", Jorge Muelle, no es otro que Jorge Muelle de la Torre Ugarte, personaje muy respetado y conocido en la Lima de fines del siglo XIX y principios del XX, quien era bisnieto del autor de la letra del Himno Nacional del Perú, don José de la Torre Ugarte y Valdivieso. (Pons, 1974: 178).

En segundo lugar, es necesario determinar qué fuentes bibliográficas de consulta sirvieron al tradicionista para sustentar la información histórica que transmite en su relato. Así, encontramos que dos son las fuentes principales de las que echó mano: De una parte, la conocida Historia Bethelehemitica. Vida Exemplar, y Admirable del Venerable Siervo de Dios y Padre Pedro De San Joseph Betancvr, Fundador del Regular Institvto de Bethlehen en las Indias Occidentales; Frvtos Singulares de sv Fecvndo Espiritv, y Sucessos Varios de esta Religion, escrita por fray José García de la Concepción editada en Sevilla en 1723, y dedicada al rey Felipe V por el R.P. fray Miguel de la Concepción ${ }^{3}$; y, de otra parte, el Bullarium Latino-Hispanicum Ord. Fratrum Bethlemitorum in Indiis Occidentalibus de Francisco Xaverio de Zelada, editado en Roma, por la imprenta de la Reverenda Cámara Apostólica, el año de 1773.

3 Esta obra erróneamente se ha atribuido en algunas bibliografías al franciscano fray Juan Carrasco de la Soledad. Es verdad que este religioso aparece en las páginas liminares de la obra, pero no es el autor de ella. Fray Juan Carrasco leyó el texto elaborado por fray José García de la Concepción para aprobar su impresión. Realizó la mencionada tarea en su calidad de Lector de Teología, y Ex-Definidor de la Santa Provincia de San Diego, de Andalucía. 
Esta afirmación se desprende luego de cotejar varios párrafos del escrito de Palma con los textos de la mencionada Historia Bethelehemitica, y lo mismo sucede con los textos que aparecen en el Bullarium o conjunto de bulas que a lo largo de los años fueron emitiendo los pontífices romanos, en beneficio de la consolidación legal o canónica del Instituto betlemítico.

\section{Personajes populares, danzantes y cantores entorno al nacimiento betlemítico}

La descripción del nacimiento, que los barbones montaban antes del 24 de diciembre y que exhibían hasta el 6 de enero en su iglesia y convento grande, no solo era primoroso por las bellas figuras centrales que conformaban el Misterio de la Natividad, sino también muy variopinto por la serie de personajes populares confeccionados en madera, yeso, porcelana y vidrio, algunos inclusive vestidos con ropajes de época; así como por los personajes vivos que recalaban en dicho recinto sagrado para bailar y cantar en su derredor. Algunos de ellos, como el mismo Palma ha señalado en su tradición, han sido también plasmados visualmente en iluminadas acuarelas que pintara "El Goya limeño", denominación encomiástica con que Palma llama al mulato Pancho Fierro, el gran pincel costumbrista de la Lima del 1800. (Stastny, 2007: 19 y ss.)

Hay que remarcar, como el mismo tradicionista lo ha puesto de manifiesto en su tradición "El mes de diciembre en la antigua Lima", que lo más interesante de dicho misterio, es el movimiento que mostraban la mayoría de personajes acompañantes del Niño Dios. $\mathrm{Al}$ respecto, leemos:

El más famoso de los Nacimientos de Lima era el que se exhibía en el convento de los padres belethmitas o barbones. Y era famoso por la abundancia de muñecos automáticos y 
por los villancicos con que se festejaba al Divino Infante. (Palma, 1957: 1199).

El dato que nos ha llegado del movimiento de los muñecos del nacimiento betlemita no es intrascendente si atendemos las palabras que César Coloma Porcari nos expresa:

Debemos resaltar esta información de Palma debido a que los muñecos automáticos que menciona, llamados "autómatas" fueron creaciones europeas realizadas generalmente en el siglo XVIII a base de instrumentos similares a los de la relojería. Eran muy costosos a principios del siglo XIX. Y es muy curioso que hubieran llegado al Perú ese tipo de autómatas y que con ellos se formara un Nacimiento. (Ibíd.)

Con respecto a la letra de las coplas y de los villancicos que se cantaban, puede decirse de ellos que en su gran mayoría han sido rescatadas del acervo popular, según lo ha precisado muy bien Coloma Porcari (2008: 43-69), y puestos en boca de algunos personajes populares de carne y hueso, que el vulgo apodaba de modo particular, tales como la "china Mónica", la "Candelita del muladar", la "Sin -monillo", el "Niño Gato", "Ño Pan-con-queso" y "Ño Cachito", o personajes que actuaban en conjunto como las llamadas pallas que "con disfraces

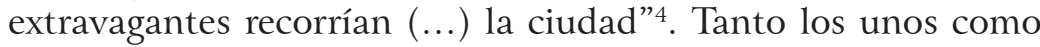
las otras, no actuaban de manera descoordinada, sino dirigidas por un director que era el maestro "Hueso" o el maestro Bañón, tipos también populares de la vieja Lima.

La importancia que tenía para los frailes betlemitas la Fiesta de Navidad, no solo era de carácter religioso, había en ella todo un componente de interacción social que merece destacarse.

4 Las payas (sic) son también mencionadas en la tradición "La Casa de Francisco Pizarro". Víd. Palma, 1957, p. 36. 
Era tiempo de algarabía, de distención y una oportunidad para compartir entre todos. Por eso, cuando los citadinos iban a contemplar el nacimiento betlemítico cada fin de año, se daba una escena como la que describe Palma:

La Virgen, San José y el Niño que movía la manita como para bendecir a los rapazuelos que los contemplábamos boquiabiertos, mientras la china Mónica, alentada por un vasito de orines del Niño, que así llamaba el pueblo a la dulcísima aloja o chicha morada con que los religiosos agasajaban a la concurrencia. (Palma, 1957: 442)

Don Ricardo Palma, con su extenso relato de "Los Barbones", ha rescatado de la oscuridad y del injusto olvido a la única Orden hospitalaria creada en la América hispana. El bien que los betlemitas hicieron en pro de la salud de los enfermos y necesitados de nuestra sociedad virreinal, e incluso de inicios de la República, no ha sido valorado del todo. A ellos hay que agradecerles especialmente el hecho de que muchos enfermos que no sobrevivieron a sus dolencias físicas, partieron serenos y reconfortados espiritualmente de este mundo con los auxilios de la religión católica que les proveyeron los frailes betlemitas.

Estando en curso el proceso de canonización del beato Pedro de San José Betancourt, y faltando solo seis años para la total extinción canónica de este Instituto religioso -que ocurre a los cien años de la muerte del último fraile-, los franciscanos de la Tercera Orden y muchos jóvenes varones con vocación hospitalaria, solicitaron a la Santa Sede restaurar la rama masculina de la Orden betlemita. Pedido que fue respondido por Juan Pablo II con la expedición de un decreto pontificio, fechado el 16 de enero de 1984, en el cual se nombró a monseñor Luis Álvarez García (fray Luis de la Cruz) como Superior-Delegado. El 25 de abril de 1986, con la profesión de los primeros religiosos de esta segunda etapa, quedó finalmente 
restaurada la Orden, de hecho y de derecho, instalándose su Casa de Gobierno y formación en San Cristóbal de la Laguna, isla de Tenerife. Asimismo, se abrió una casa de formación en Guatemala, en donde trescientos años antes el humilde hermano Pedro de San José, había sembrado la primera semilla de la Orden con el propósito de aliviar las dolencias de los enfermos más necesitados, pero, sobre todo, para dar con ello gloria eterna a Dios.

\section{Bibliografía}

Augustín, R. (2012). Las Murallas Coloniales de Lima y el Callao. Lima: Editorial Universitaria de la Universidad Ricardo Palma.

Córdova, J. M. (1992). Estadística histórica, geográfica, industrial y comercial de los pueblos que componen las provincias del departamento de Lima. (Edición facsimilar de la edición de 1839 con prólogo e índices de César Coloma Porcari; Presentación de Rosa Larco de Miró Quesada). Lima: Sociedad "Entre Nous".

Coloma, C. (1998). La Ciudad de los Reyes y la "Guía del Viajero en Lima" de Manuel Atanasio Fuentes. (Edición facsimilar de la edición de 1860). Lima: Instituto Latinoamericano de Cultura y Desarrollo.

(2007). La culinaria peruana en las Tradiciones de Ricardo Palma: En Aula Palma VI, Lima: Editorial Universitaria de la Universidad Ricardo Palma, pp. 169-214.

(2008). La Música y la danza en las Tradiciones de

Ricardo Palma. En Aula Palma VII. Lima, Editorial Universitaria de la Universidad Ricardo Palma, pp. 43-69.

(2011). La flora del Perú en las Tradiciones de Ricardo Palma. En Aula Palma X. Lima: Editorial Universitaria de la Universidad Ricardo Palma, pp. 61-90. 
(2016). La Navidad y la Epifanía en las Tradiciones de Ricardo Palma. En Aula Palma XV. Lima: Editorial Universitaria de la Universidad Ricardo Palma, pp. 169-181.

Díaz, J. (2015). Cronología de las Tradiciones Peruanas. (Tercera edición aumenta y corregida con nueve ilustraciones de Luis Eduardo Cassaró Bolarte). Lima: Editorial Universitaria de la Universidad Ricardo Palma.

Fernández, E. (2000). Perú cristiano. Primitiva evangelización de Iberoamérica y Filipinas, 1492-1600, e Historia de la Iglesia en el Perú, 1532-1900. Lima: Fondo Editorial de la Pontificia Universidad Católica del Perú.

Fuentes, M.A. (1860). Guía Histórico-Descriptiva, Judicial y de Domicilio de Lima. Lima: Librería Central.

(1867). Lima. Apuntes Históricos, Descriptivos, Estadísticos y de Costumbres. París: Librería de Firmin Didot hermanos, hijos y Ca.

Gálvez, J. (1943). Calles de Lima y meses del año. Lima: International Petroleum, Co. Ltd.

García, J. (1956). Historia Belemitica. Vida ejemplar y admirable del Venerable Siervo de Dios, y padre Pedro de San José Betancur, Fundador del Regular Instituto de Belén. (Prólogo del Dr. Carmelo Sáenz de Santa María, S.J.), Guatemala: Biblioteca "Goathemala" de la Sociedad de Geografía e Historia de Guatemala, segunda ed., vol. XIX.

Klaiber, J. (1996). La Iglesia en el Perú. Lima: Fondo Editorial de la Pontificia Universidad Católica del Perú.

Martínez-Palomero, P. (1992). El Belén. Historia, tradición y actualidad. Madrid: Aura Comunicación. 
Orrego, J.L. (2017). Los 'betlemitas' en Lima. Recuperado de http:// blog.pucp.edu.pe/blog/juanluisorrego/201 1/1 1/08/losbetlemitas-enlima/

Palma, R. (1957). Tradiciones Peruanas Completas. (Edición y prólogo de Edith Palma, nieta del autor). Madrid: Aguilar.

(2015). Tradiciones Peruanas. Séptima/ Octava Series. (Edición, prólogo, notas, bibliografía e índices de Miguel Ángel Rodríguez Rea). Lima: Editorial Universitaria de la Universidad Ricardo Palma.

Pérez-Palacio, S. M. (1944). La Orden Bethlemítica y su labor hospitalaria y educativa en el Perú durante el virreinato. (Tesis inédita de Historia). Lima: Facultad de Letras y Ciencias Humanas, Pontificia Universidad Católica del Perú.

Pons, G. (1974). Símbolos de la Patria. Colección Documental de la Independencia del Perú. Tomo X. Lima: Comisión del Sesquicentenario de la Independencia Nacional.

Prince, C. (2011). Lima Antigua. Tipos de Antaño con numerosas viñetas. (Edición facsimilar de la edición de 1890). Lima: Casa del Libro Viejo.

Reyes, A. (2015). Barrios Altos. La otra historia de Lima. Siglos XVIII$X X$. Lima: Fondo Editorial de la Universidad Nacional Mayor de San Marcos.

Rodríguez, M. A. (2007). Ricardo Palma y los jesuitas. En Aula Palma VI, Lima: Editorial Universitaria de la Universidad Ricardo Palma, pp. 233- 246.

Stastny, F. (2007) Acuarelas de Pancho Fierro y seguidores. Colección Ricardo Palma. Lima: Municipalidad Metropolitana de Lima- Pinacoteca Municipal Ignacio Merino. 
Vorágine, J. (2003). El libro de la Navidad. Madrid: Ediciones Encuentro, S.A.

Zelada, F. X. (1773). Bullarium Latino-Hispanicum Ord. Fratrum Bethlemitorum in Indiis Occidentalibus. Romae: Typis, Reverendae Camerae Apostolicae.

Recibido el 29 de noviembre del 2017

Aceptado el 17 de diciembre del 2017 